\title{
The Relationship between Culture Exposure and the Identity Types of Learners of English as a Foreign Language
}

\author{
Akbar Afghari ${ }^{1}$, Zahra Tavakkoli $^{1}$, Fatemeh Rakhshandehroo ${ }^{2, *} \&$ Mohammad Ali Izadpanah $^{2}$ \\ ${ }^{1}$ Department of Foreign Languages and Linguistics, Sheikh Bahaee University, Esfahan, 81797-35296, Iran \\ ${ }^{2}$ Department of Foreign Languages and Linguistics, Shiraz University, Shiraz, 71964-85115, Iran
}

*Corresponding author: Fatemeh Rakhshandehroo, Department of Foreign Languages and Linguistics, Shiraz University, Shiraz, 71964-85115, Iran. Tel: +98-917-713-2520. E-mail: nedarakhsh62@gmail.com

Received: August 13, 2012

Accepted: August 26, 2012

Published: September 25, 2012

doi:10.5430/wjel.v2n3p14

URL: http://dx.doi.org/10.5430/wjel.v2n3p14

\begin{abstract}
The way mankind defines himself is believed to be highly sensitive to the cultural norms and values of the culture he is brought up in. The present study was carried out in order to explore any probable impact of foreign culture exposure on identify types of EFL learners. The participants $(\mathrm{N}=98)$ consisted of male and female intermediate EFL learners who were studying English at two language institutes in Shiraz. They were randomly selected from the same proficiency level and randomly divided into two experimental and two control groups. The participants in the experimental groups were exposed to the target language culture, roles, values, and beliefs for ten weeks in order to observe whether they had moved towards the target language identity based on Erikson's theory of psychosocial development (Erikson, 1958, 1963). Two versions of the Ego Identity Process Questionnaire (EIPQ), as an ego identity type recognizer, were administered both at the beginning and at the end of the semester. The difference in mean between the groups involved in the present research was measured by a T-test. Further analysis was based on P-value as a scale used to retain or reject the null hypothesis. The findings of the present study revealed that the learners' identities do not change significantly through exposure to foreign culture, beliefs, values, and roles, although some minor changes were detected which were not statistically significant. Some pedagogical suggestions were also made for Iranian educational policy makers.
\end{abstract}

Keywords: Ego identity, Cultural identity, Culture, Cultural norms

\section{Introduction}

The interaction between learning a language and the different aspects of identity formation and types has been addressed from diverse angles. Language learners and language teachers, among many other issues, have to deal with a plethora of factors, their perspectives towards the target language culture being one of the most controversial ones. Recent studies in SLA have mainly focused on the need to understand the interests, motivations, expectations and needs of the language learners' in order to comprehend the educational implications of the cultural and linguistic differences that are found to be increasingly decisive in shaping ego identity types. At the core of the current thinking trend in language learning is the assumption that acquisition of linguistic input should prepare learners for "new forms of social participation and link our learners' communities, real, virtual, and imagined, with those of their counterparts in other cultures and worlds" (Luke \& Elkins, 1998).

Learning a foreign language may influence the learners' identity. The effects of foreign language may be assimilating and/or dissimilating meaning that foreign language learners may move toward more or less identical ego identity characteristics (which mainly consist of target language characteristics) or far away from them. Coming to a full picture of these two possibilities would affect the language specialists' efforts to equip their learners with the most 
efficient teaching methodologies.

To the researchers' knowledge, the investigation of the possible effects of foreign culture exposure on identity types of EFL learners has been ignored to a large extent on the part of language specialists and even psychologists during the past five decades. If identity is considered as an inner eye whatever data is received from the outside world, including language, is monitored by our identities. Since language and culture are believed to be two sides of the same coin, the investigation of the effect of culture on identity not only sounds fruitful but also appears to be inevitable.

\section{Literature Review}

The main piece of each individual's actual identity consists of a sense of continuity, a sense of uniqueness from others, and a sense of affiliation. Identity helps individuals recognize themselves as separate and distinct entities (Piller, 2007). Based upon the context in which it appears, identity may function differently and have different kinds of influence on the context in which it is found.

As reported by Anthis\&LaVoie (2006) a person begins to change in terms of identity as a result of internal realizations and/or inconsistent external feedback and one of the main contexts which provides this external feedback, and is the focus of the present research, is the foreign language learning context. In order to fully grasp the meaning of identity change it seems essential to elaborate on the importance of identity exploration and formation. Over the years, the process of identity exploration has been viewed as a crucial component of identity formation (Grotevant, 1987). Marcia (1966) conceptualized exploration as one of the two basic dimensions of identity formation, the other one being identity commitment. On the other hand, Berzonsky (1990), in an attempt to capture the social-cognitive processes underlying identity exploration, expanded Marcia's bipolar framework by proposing three identity processing styles. He conceptualized the information-oriented identity style as the social-cognitive style underlying a pro-active, thorough, and broad-based identity exploration (Soenens, Duriez, \&Goossens, 2005).Having all these issues in mind, it can be concluded that one's identity is completely inseparable from the cultural norms of the society.

Culture, as a set of values, norms, and scripts, is likely to affect the identity, attitudes, beliefs, and behaviors of individuals (Singleton, 2000). In this sense, cultural orientation is related to but distinct from types of self-definitions (e.g., individual, relational, and collective). Self-definitions are about oneself, whereas cultural orientation is about an individual's perception of what is valued/normative in the culture.

Communication in the target language not only requires proficiency of the social context in which language must be used, but also the socio-cultural rules that govern language and discourse (Asref, 2002). According to this point of view, one of the main roles of a teacher would be to transform the student into someone who a native speaker would consider to have linguistically and socio-culturally appropriate behavior. Hence, teaching a culture transforms into the main core of language teaching. A second approach considers the classroom as an environment within which the language must be taught and not the culture. In this view, teaching a specific culture may mistakenly imply that the native culture is an inferior culture and the target culture is a superior one. A final middle approach may be considered as teaching a second language and the culture associated with it rather critically. In this approach, the culture is not only taught, but also scrutinized honestly. The target culture (TC) is taught, and learners supervised to discuss, criticize, compare, and contrast the TC with their own culture. Most often, by honest scrutinizing of both cultures, the classroom would conclude that every culture has its own strengths and weaknesses.

In the past few decades, teaching a language and adapting the relevant culture have been closely linked. This is specifically emphasized by those who see English language as a social practice. According to their view, the main goal of teaching a foreign or second language is to enable the learners to use the language for communication purposes; a process that most likely occurs in the target community.

Teaching and learning culture in a classroom is bound to have its own challenges and difficulties. The main challenge arises where cultures have different points of view on a certain subject and the probable effects of such difference on the learners' identity. Such a subject may be a social, political, religious, or even economical matter. The problem is that there is always a severe concern about the possible effects of learning a new culture on the identity of learners. According to $\mathrm{Gu}$ (2010) while most empirical studies of national identity in the field of language learning focus on the experiences of immigrant learners in host countries, relatively few studies examine the influence of L2 learning on the national identity of learners who study an L2 in their mother country. In his longitudinal inquiry into national identity in EFL learning, $\mathrm{Gu}$ (2010) considers the context of learning in China which boasts the largest number of English learners in the world and where a sense of national identity has always been fostered through education, for a study investigating the national identity construction among those who learn English as an L2. His study captures the 
changes learners have experienced in constructing identities over a prolonged period in the context of mainland China where strong sense of national identity has been historically promoted and where there is currently unprecedentedly close interaction between local cultures and western cultures. Drawing on interviews and diary studies as the primary data source, this study identifies a three-stage development in the national identities of the college learners that proceeds from initial admiration of English-speaking cultures, to antagonism towards alien things, before then reaching a stage of conciliation between the national and the global. The findings suggest that China's deeply-rooted culture of collectivism and altruism plays a role in shaping English learners' national identity and that the learners also demonstrate considerable agency in constructing national identities at different stages of English learning. The four English learners in this study experienced changes in national identity during their college years. Their experiences reflect those of many college English learners. The results of Gu's study (2010) suggest that EFL learning in the Chinese context is more than just the simple accumulating of language knowledge and skills; rather, it plays an important role in shaping and constructing learners' national identities. The results indicate that learning English as an L2 leads to a heightened appreciation of the local culture. They also suggest that English learning is imbued with an interaction between learners' national and imagined global identities, and that the learners in this study demonstrate considerable agency in constructing national identity when they interact with dominant social discourses.

\section{Objectives and Significance of the study}

The present study is an attempt to investigate whether teaching the culture, beliefs, and values of the target society through the tool of language, in other words foreign culture exposure, can affect the cultural beliefs and values of foreign language learners and consequently their identity types. The extent to which such an alteration might occur will be studied. This study can be also used as a platform for educational policy makers, material developers, curriculum designers, teacher educators, and at the most basic level dynamic teachers active in the field of EFL.

\section{Method}

\subsection{Subjects}

The participants in this study were 98 male and female intermediate learners who were studying English at Soha and Bahar language institutes in Shiraz. The sample was compromised of 4 groups, two experimental $(17 \mathrm{female}=17 \%$, 26 male $=27 \%$ ) and two control groups ( 38 female $=38 \%, 17$ male $=18 \%$ ). The participants' age ranged from 16 to 28 with an average of 19. The participants were randomly selected from the same proficiency level and were randomly divided into experimental and control groups.

The participants in the experimental groups were exposed to the culture, values, beliefs, religion, occupational rules, dating rules, sex roles, etc. of the target language society by watching purposefully selected movies, giving lectures, and via discussions based on Erikson's theory of psychosocial development (Erikson, 1958, 1963) while the control groups consisted of learners who were merely exposed to the linguistic components of the language without incorporating the cultural values of the target language into the curriculum.

\subsection{Instruments}

Identity types of the learners were assessed by a translated version of the Ego Identity Process Questionnaires (EIPQ) (Appendix B) which is the revised and modified version of the extended version of the Objective Measure of Ego Identity Status (EOM-EIS) by (Bennion\& Adams, 1986). This version of EIPQ is composed of 32 items which are randomly ordered across the two dimensions of exploration and commitment and eight domains of occupation (e.g., "I have tried to learn about different occupational Weldsto find the best one for me.") religion (e.g., "I have considered adopting different kinds of religious beliefs."), politics (e.g., "I have considered different political views thoughtfully."), values(e.g., "My values are likely to change in the future."), family(e.g., "I have not felt the need to reflect upon the importance I place on my family."), friendship(e.g., "I have had many experiences that led me to review the qualities I would like my friends to have."), dating(e.g., "I have questioned what kind of date is right for me."), and sex roles(e.g., "I have undergone several experiences that made me change my views on men's and women's roles."). Sixteen of the EIPQ's items measure identity exploration, and the remaining sixteen items measure identity commitment. Respondents indicate their degree of agreement to each statement on a 6 - point Likert - scale.

\subsection{Procedure}

The participants of this study were divided to four classes. Both experimental groups were taught by the researchers themselves. For the purposes of this study, in the experimental groups the learners were explicitly exposed 
to culture-bound concepts, values, and religious elements of the target language society by the use of movies, music, and student lectures. But this treatment was absent in the control groups.

The researchers attended relevant institutes to collect the data in person. Having provided the participants with sufficient information with regard to how the items should be answered, the questionnaires were distributed once at the beginning of the semester and later on at the end of the semester after about 10 weeks of exposure.

Two versions of the same EIPQ were administered once on April 6, 2010 and later on June 16, 2010 to a total of 98 learners, the difference merely residing in the order of the questions. The purpose behind administering the EIPQ was to determine the identity type of the participants. The re-administration of this test provided the researchers with a situation in which perfect comparison could be made between the two groups in terms of identity change. After the collected data was categorized and codified, the Statistical Packages for Social Sciences (SPSS) version 17.5 and the Minitab-15 were utilized for data analysis. Descriptive statistics including T-test was also extracted from the data in order to compare the mean scores of the groups from whom the data was collected.

\section{Results and Discussion}

This section provides the results of the statistical analyses of the collected data. The following hypotheses were formulated. Based on the proposed null hypothesis it was believed that a fifty percent change in the learners' identity types cannot be considered as a significant one while based on the first hypothesis of the current research more than fifty percent of change in the learners' identity types can be considered as significant. The results are shown in Figures 1-12 and Tables 5.1-5.6 in Appendix A. The relevant explanations for Figures 1-12 and Tables 5.1-5.6 are provided here. It should be noted that the mentioned percentages of changes found in each group after exposure to target culture has been approximately reported.

In the beginning of the semester the percentages of ego identity in the experimental groups (male and female) were formulated as follows: identity achieved $25.58 \%$, identity diffused $18.60 \%$, identity moratorium $6.98 \%$, and identity foreclosed $48.84 \%$ (Figure 1). At the end of the semester, these percentages changed to identity achieved $41.86 \%$, identity diffused $25.58 \%$, identity moratorium $4.65 \%$, and identity foreclosed $27.91 \%$ (Figure 2 ). As one might have noticed there were some drastic increases in achieved (16\%) and diffused groups (7\%). Moratorium and foreclosed, on the other hand, faced a decrease in number.

Male participants who are considered foreclosed and moratorium were found to decrease, foreclosed $35 \%$ and moratorium 3\%, while achieved and diffused male participants increased in number (Figure 3\&4). These increases were also seen in achieved (23\%) and diffused (15\%) male participants which were the only changes considered as significant by SPSS. On the other hand, female foreclosed and moratorium participants performed exactly the same on both questionnaires whereas percentages of diffused female participants decreased and achieved increased in number (Figure 5\&6).However, SPSS considered the changes observed amongst female participants as quite insignificant.

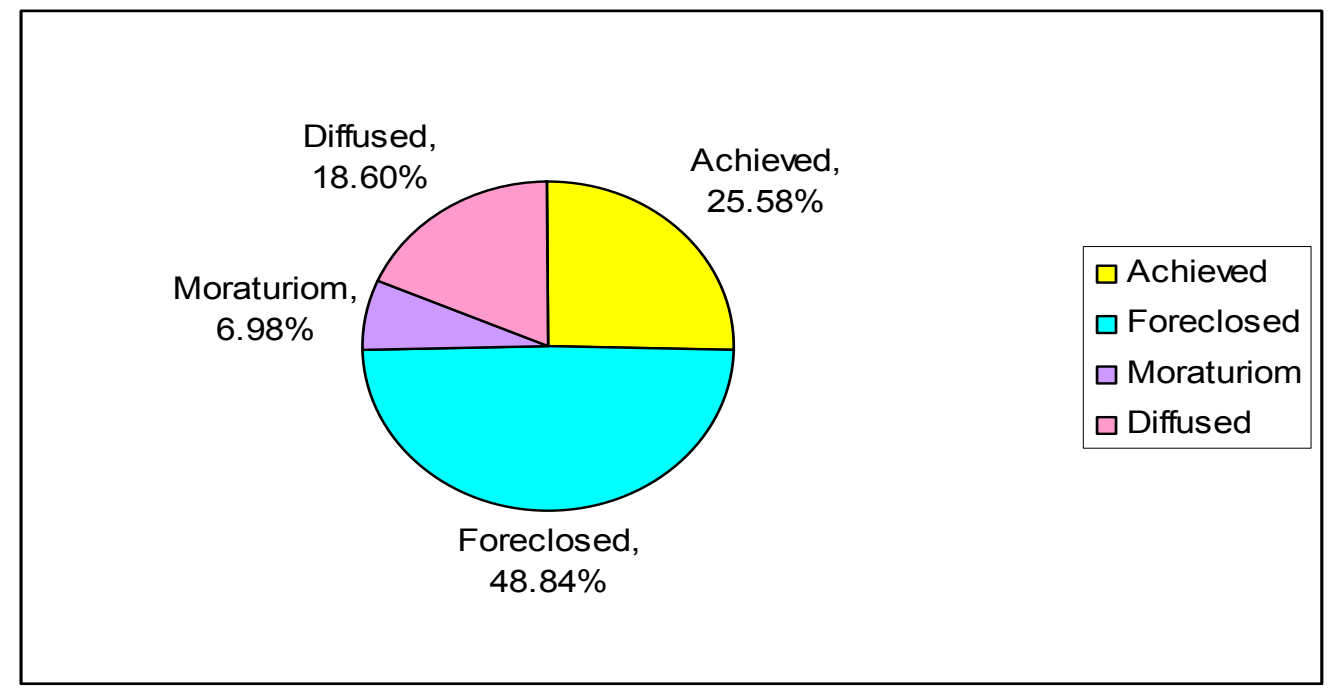

Figure 1: Circular diagram of ego identity in the experimental groups before exposure 


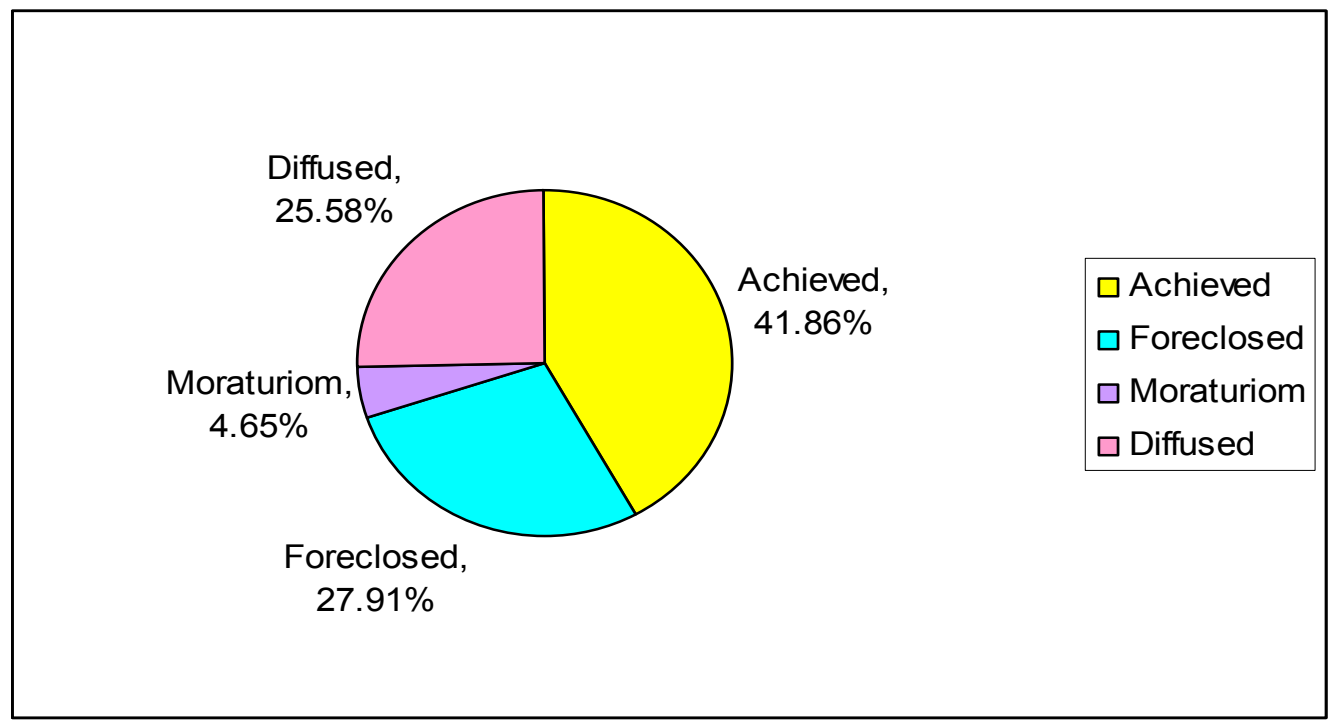

Figure 2: Circular diagram of ego identity in the experimental groups after exposure

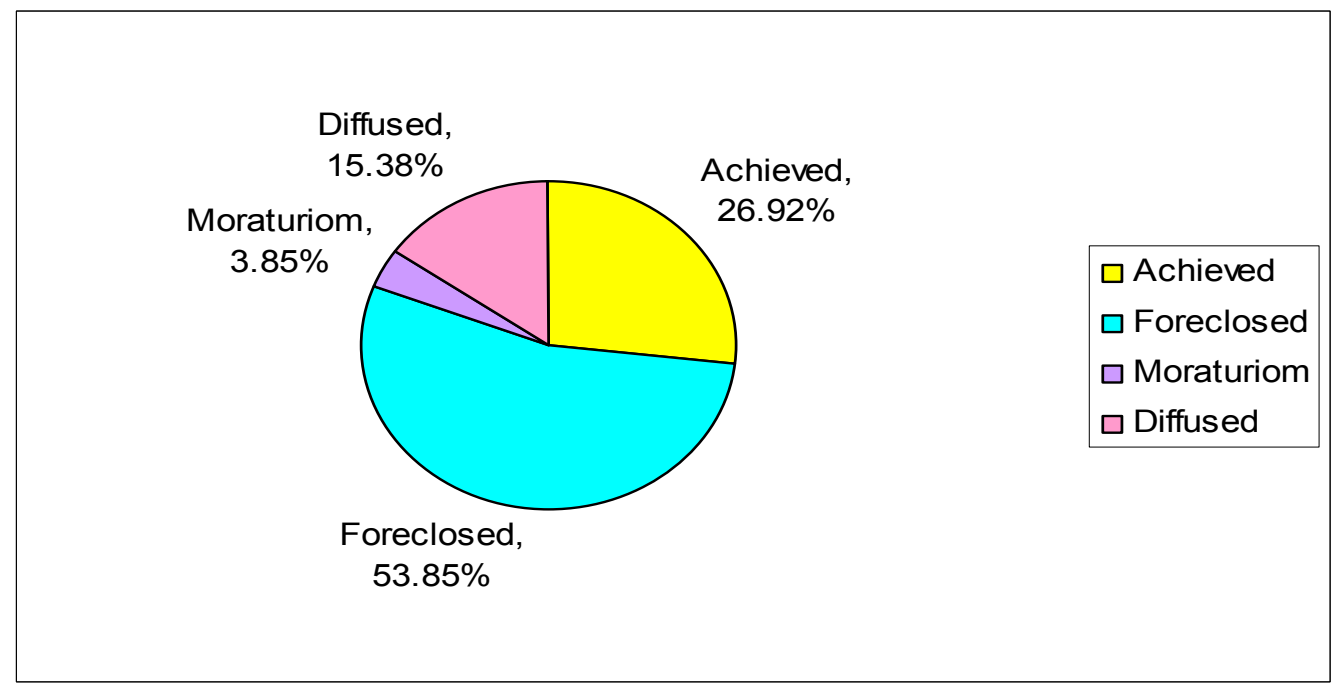

Figure 3: Circular diagram of ego identity of males in the experimental group before exposure 


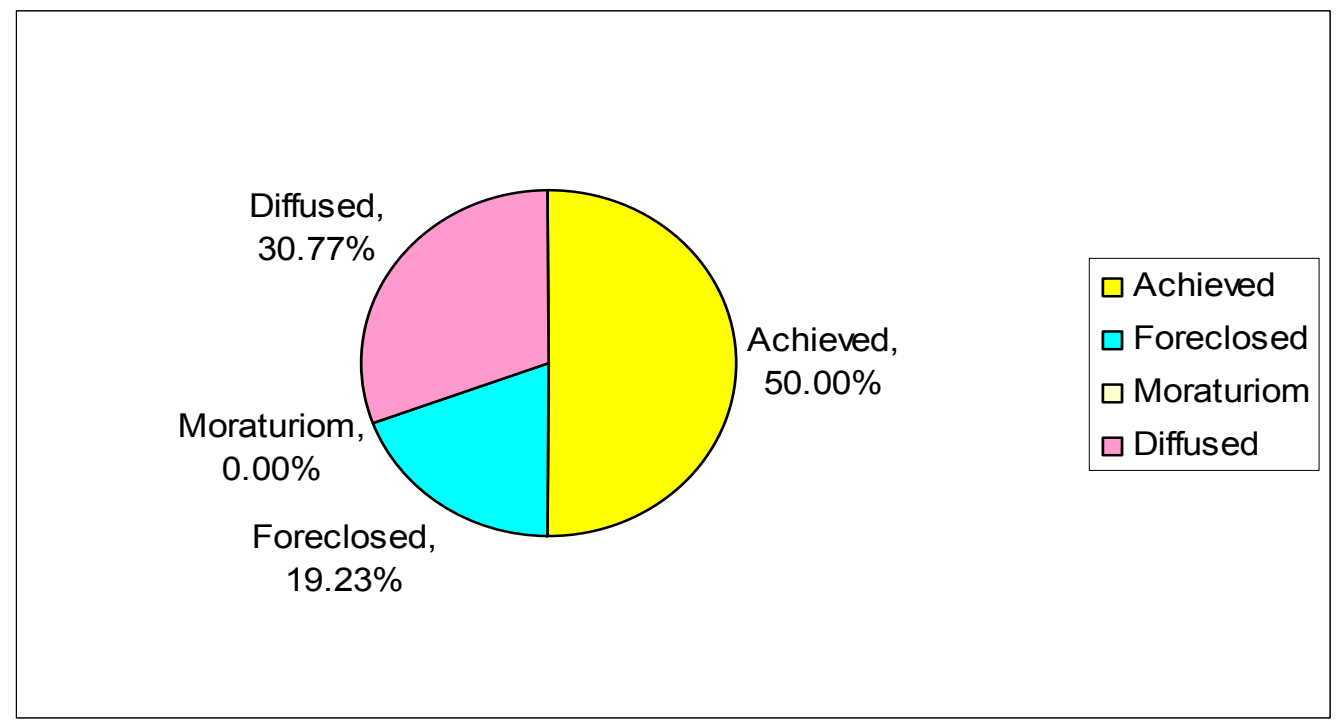

Figure 4: Circular diagram of ego identity of males in the experimental group after exposure

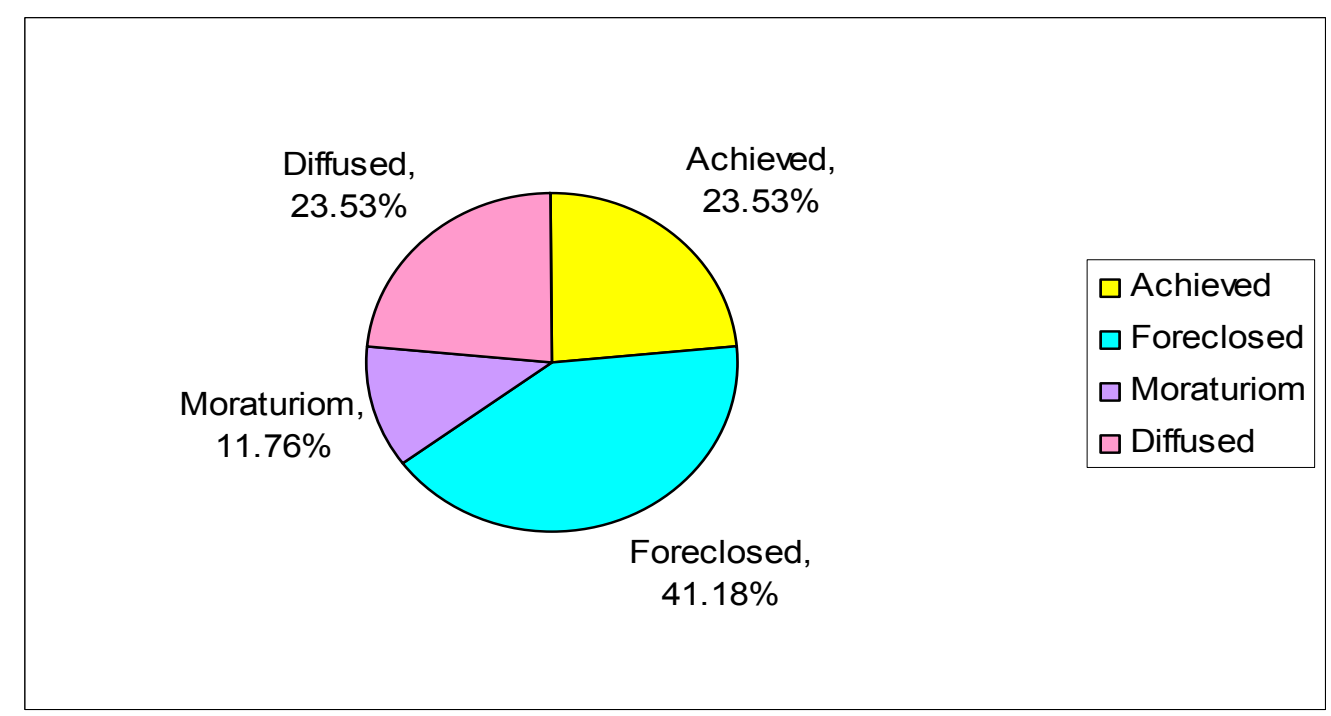

Figure 5: Circular diagram of ego identity of females in the experimental group before exposure 


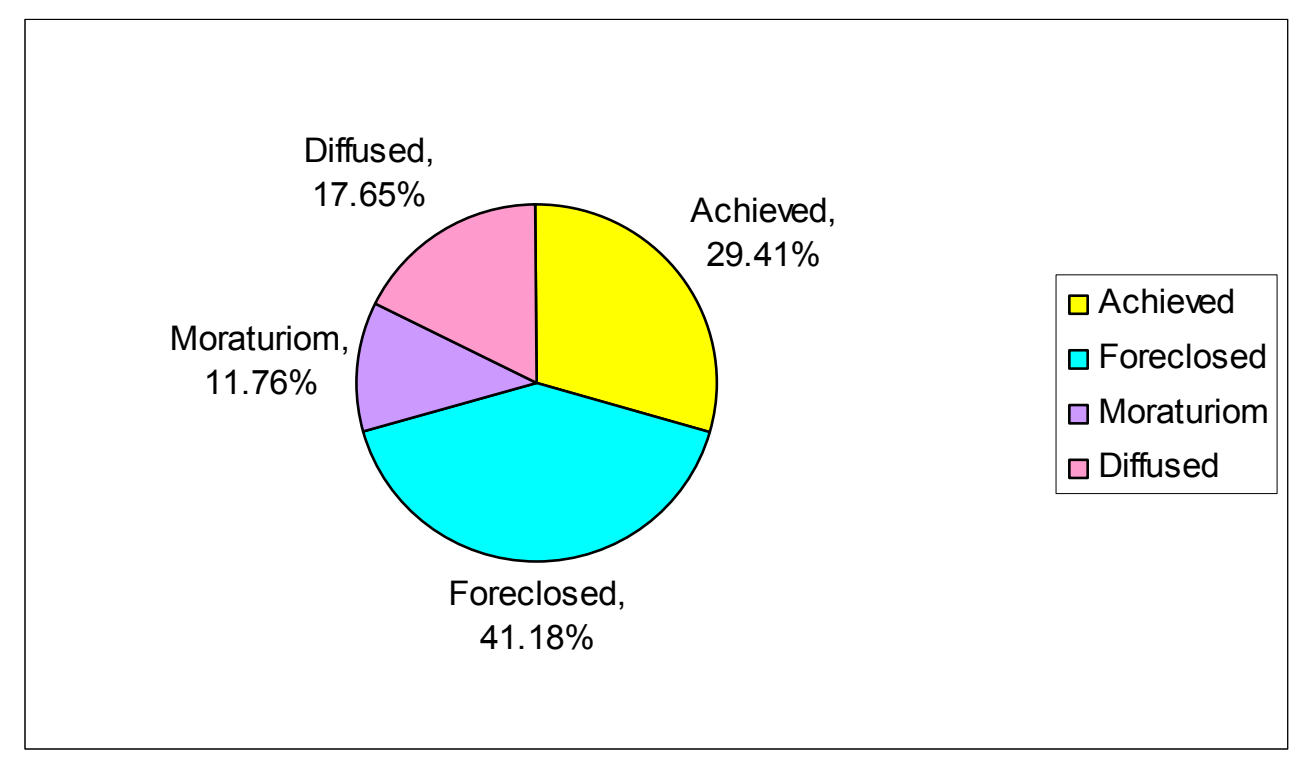

Figure 6: Circular diagram of ego identity of females in the experimental group after exposure

$$
\text { H0: } p=0.5
$$

$\mathrm{H} 1: \mathrm{p}>0.5$

In the beginning of the semester the percentages of ego identity in the control groups (male and female) were formulated as follows: identity achieved $20 \%$, identity diffused $27.27 \%$, identity moratorium $12.73 \%$, and identity foreclosed $40 \%$ (Figure 7). At the end of the semester, these percentages changed to identity achieved $18.18 \%$, identity diffused $29.09 \%$, identity moratorium $9.09 \%$, and identity foreclosed $43.64 \%$ (Figure 8 ). As it is shown in the two above mentioned figures there was a close to $4 \%$ change in identity moratorium and identity foreclosed as well as some changes in the other two types of ego identity.

Male participants who are considered as achieved and moratorium were found to decrease while foreclosed and diffused male participants increased in number (Figure 9\&10). On the other hand, female achieved and diffused participants performed exactly the same on both questionnaires whereas percentages of moratorium female participants decreased and foreclosed increased in number (Figure 11\&12). However, all these changes were considered to be insignificant by SPSS and could, therefore, be caused due to the effect of factors rather than that of foreign culture exposure. 


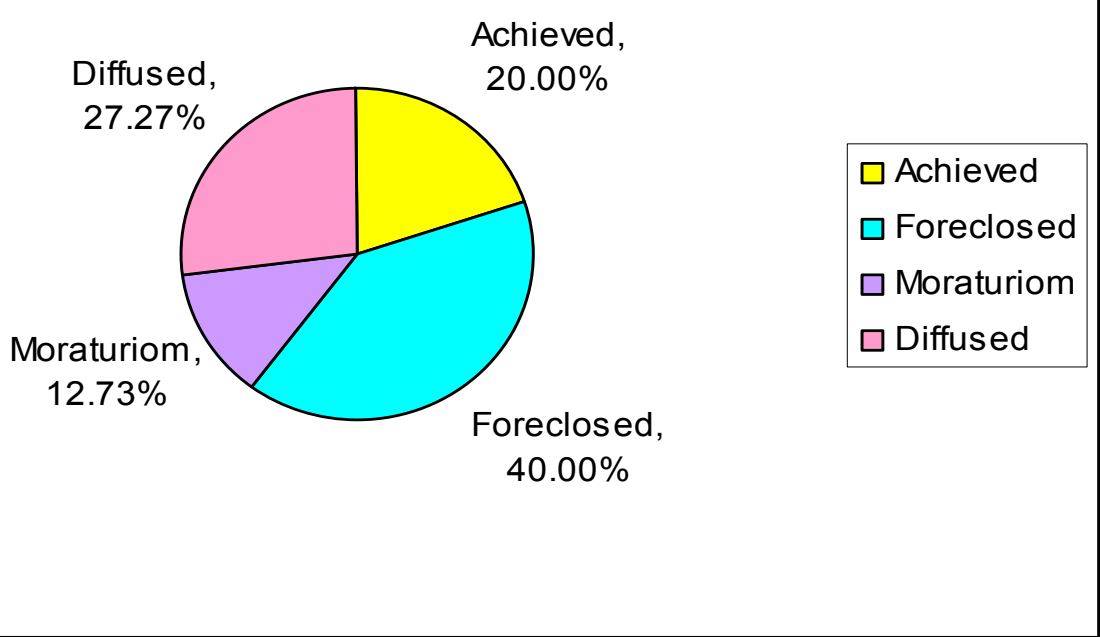

Figure 7: Circular diagram of ego identity in the control groups before exposure

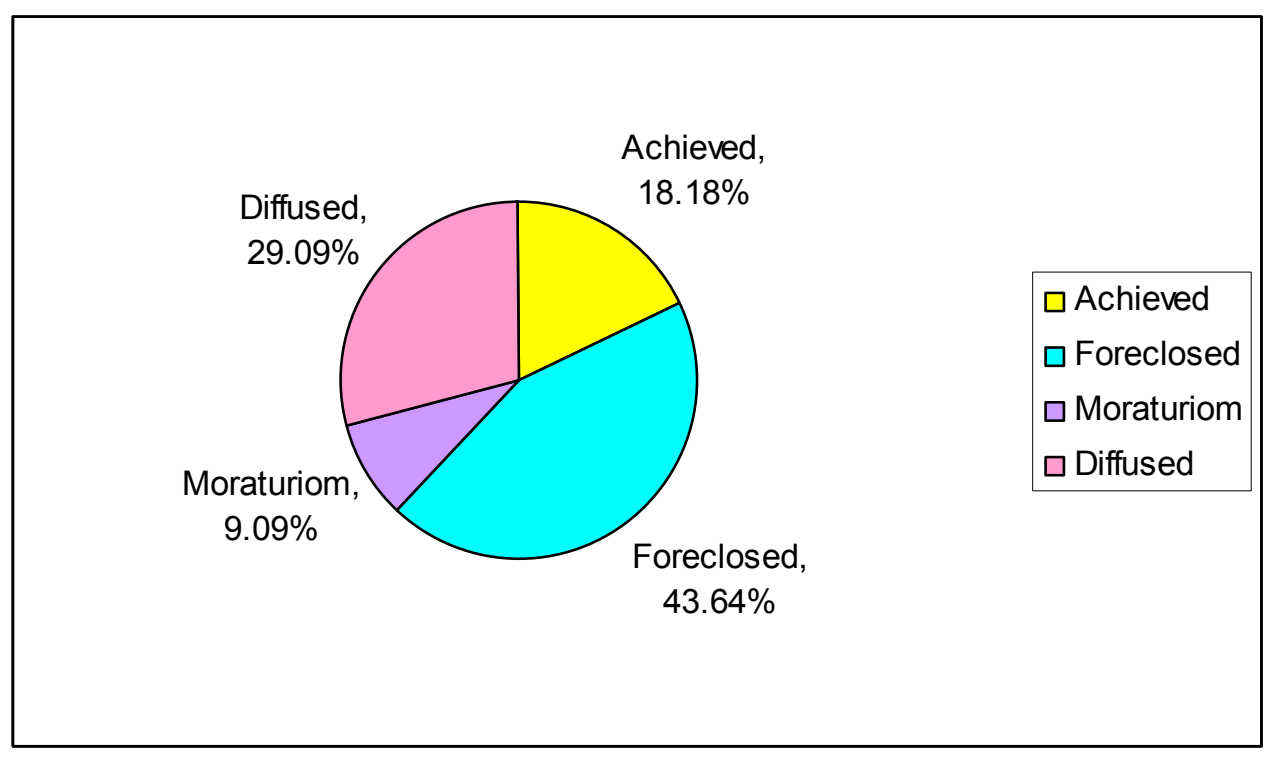

Figure 8: Circular diagram of ego identity in the control groups after exposure 


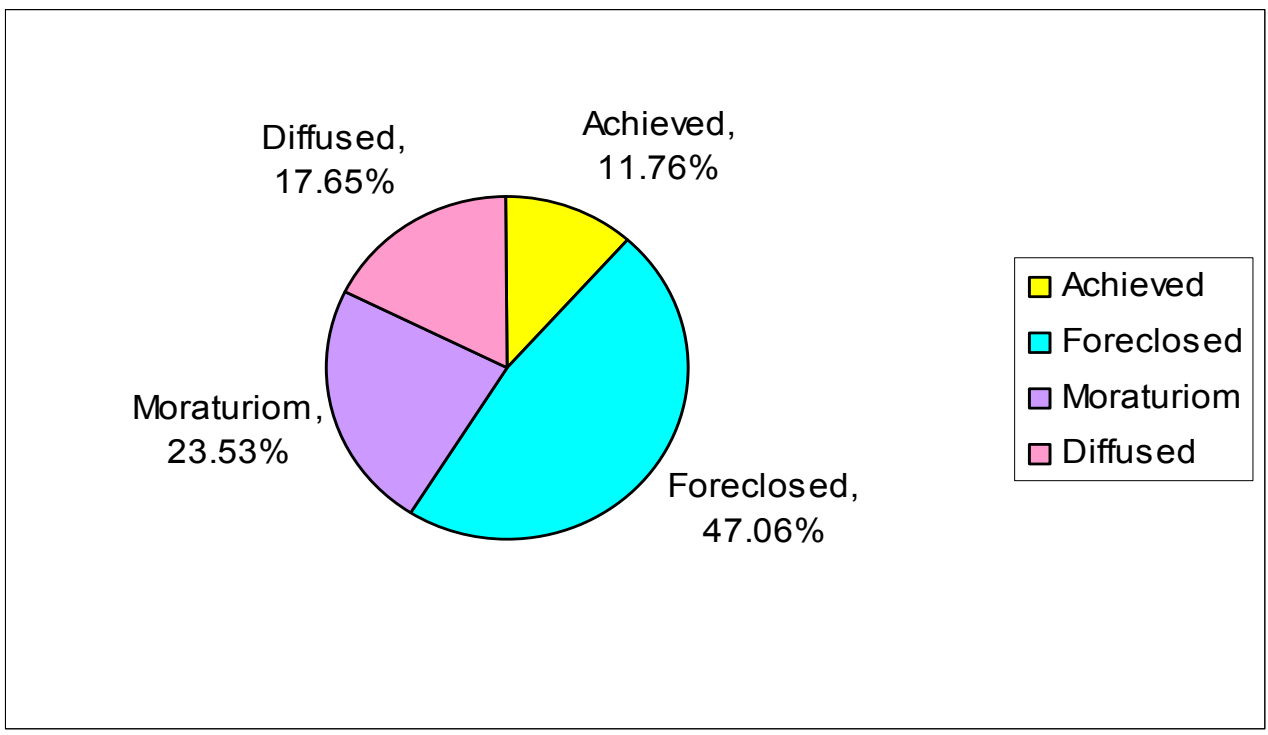

Figure 9: Circular diagram of ego identity of males in the control group before exposure

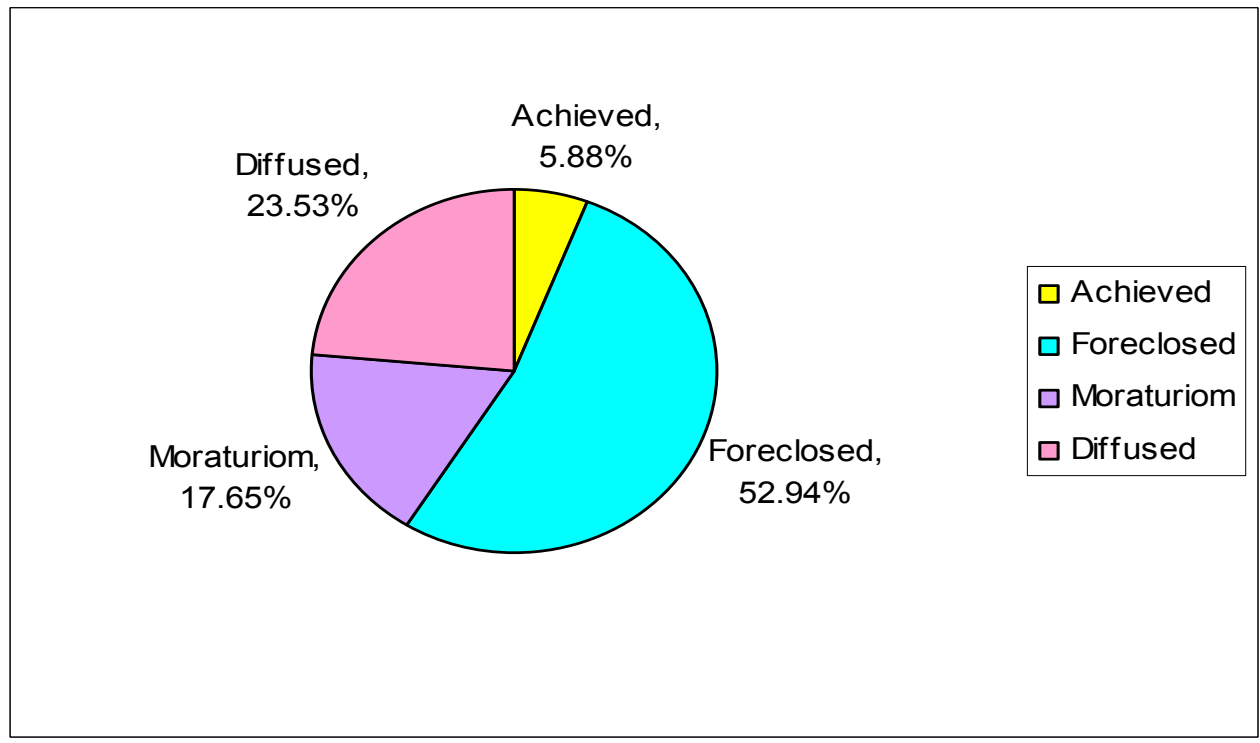

Figure 10: Circular diagram of ego identity of males in the control group after exposure 


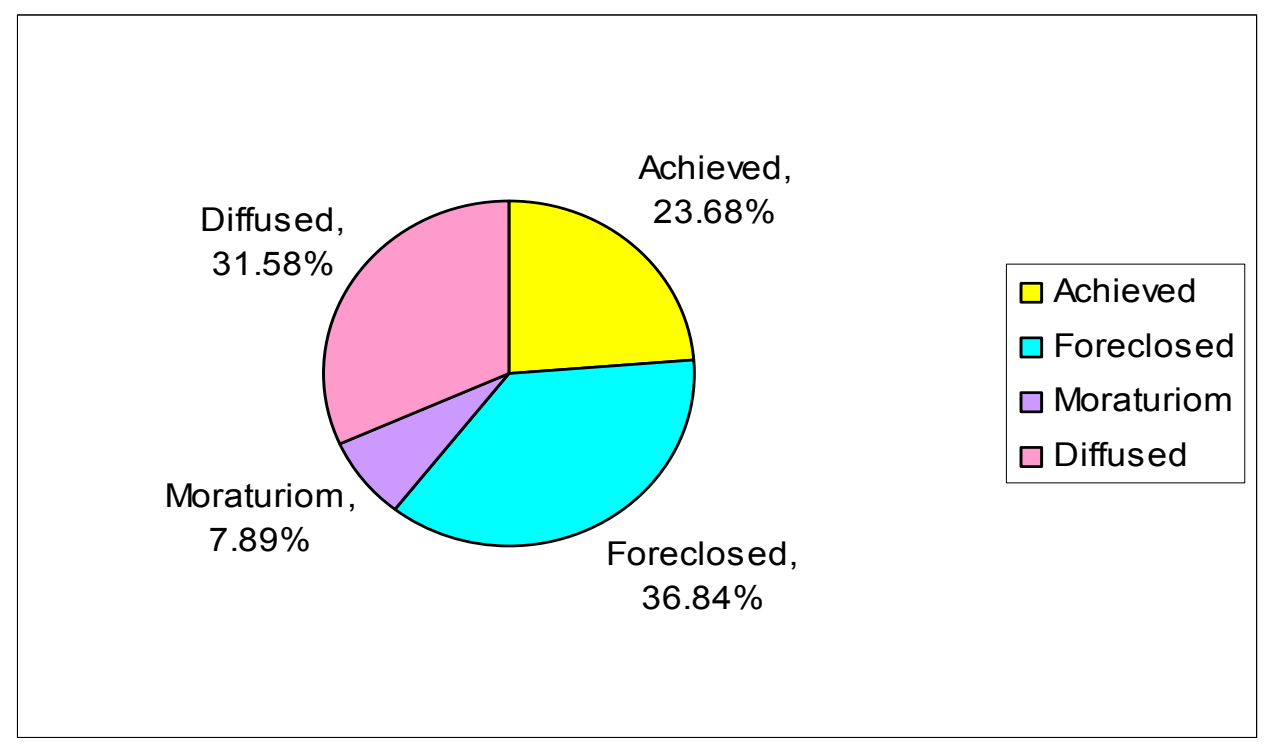

Figure 11: Circular diagram of ego identity of females in the control group before exposure

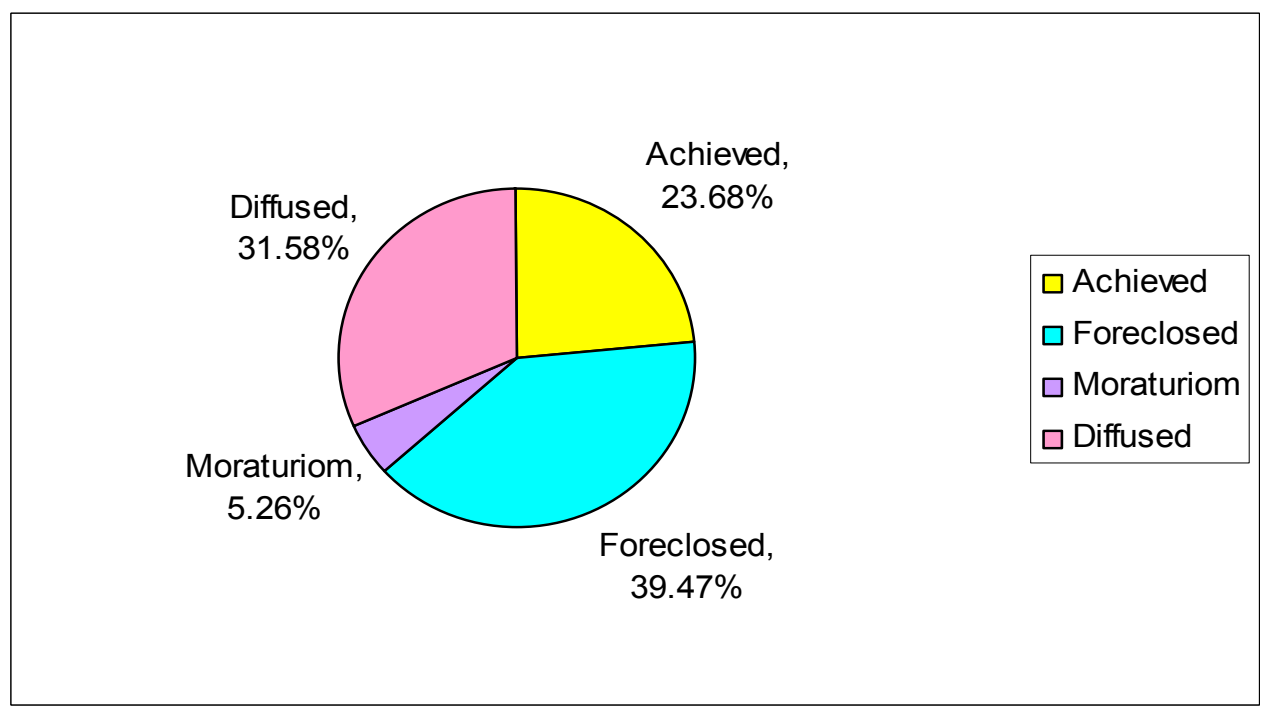

Figure 12: Circular diagram of ego identity of females in the control group after exposure

It can therefore be concluded that the females in both the control and experimental groups did not significantly change in terms of identity types while, interestingly, male participants in experimental groups significantly performed differently on the questionnaire which indicates a change in their ego identity types.

As shown in table 5.1, twenty-six out of forty-three learners in the experimental group have changed in terms of identity types due to exposure to the culture of the foreign language. The P-value is equal to 0.111 which shows that this change is not considered as significant because $0.111>0.05$ and the null hypothesis is accepted. It is at the 0.1 level this change can almost be considered as significant. 
Table 5.1: Identity change in the experimental group

\begin{tabular}{lcccccc}
\hline & & & & $95 \%$ & Lower & Exact \\
\hline Variable & $\mathrm{X}$ & $\mathrm{N}$ & Sample $\mathrm{p}$ & Bound & P-Value \\
C1 & 26 & 43 & 0.604651 & 0.467848 & 0.111 \\
\hline
\end{tabular}

As depicted in table 5.2, thirteen out of fifty-five learners in the control group have changed in terms of identity type. Here the P-Value is equal to 1.00 which shows that the data supports the null hypothesis by a high amount of certainty. This means that this hypothesis is accepted and the hypothesis of identity change is rejected without any doubt.

Table 5.2: Identity change in the control group

\begin{tabular}{lrrrrrr}
\hline & & & & $95 \%$ & Lower & Exact \\
\hline Variable & $\mathrm{X}$ & $\mathrm{N}$ & Sample $\mathrm{p}$ & Bound & P-Value \\
C.group & 13 & 55 & 0.236364 & 0.145847 & 1.000 \\
\hline
\end{tabular}

In order to indicate the effect of gender on identity change due to L2 cultural exposure the experimental and control groups were further studied in terms of their gender types. As indicated in table 5.3, seventeen out of twenty-six identities of males' in the experimental group have changed. This change is not significant at the .05 level because $.084>0.05$ and $\mathrm{H} 0$ is accepted. But it can be considered as significant at 0.1 level since $0.084<0.1$ and $\mathrm{H} 0$ is rejected. So we can say that the males in the experimental group have changed after about three months of exposure.

Table 5.3: Identity change in the male experimental group

\begin{tabular}{llllllll}
\hline \multicolumn{9}{c}{$95 \%$} & Lower & Exact \\
\hline Variable & $\mathrm{N}$ & $\mathrm{N}$ & Sample $\mathrm{p}$ & Bound & P-Value \\
e.group.male & 17 & 26 & 0.653846 & 0.473838 & 0.084 \\
\hline
\end{tabular}

As we see in table 5.4, 9 females out of 17 in the experimental group have changed. This number shows that about 52.9 percent of learners have changed which should be considered as significant. But the Minitab does not support this idea. Based on the Minitab we see that because $0.5>0.05$ and $0.5>0.1$, H0 is accepted at both the 0.05 level and the 0.1 level.

Table 5.4: Identity change in the female experimental group

\begin{tabular}{lcccccc}
\hline \multicolumn{5}{c}{$95 \%$ Lower Exact } \\
\hline Variable $\quad \mathrm{X}$ & $\mathrm{N}$ & Sample p & Bound & P-Value \\
e.group.female & 9 & 17 & 0.529412 & 0.310830 & 0.500 \\
\hline
\end{tabular}

Based on table 5.5, only 3 out of 17 males in the control group have changed. This means that the males' identities have not changed significantly during the semester. The P-Value also affirms this idea by a high range of certainty. As we see $\alpha$ is equal to 0.99 and $\mathrm{H} 0$ is accepted at both levels. 
Table 5.5: Identity change in the male control group

\begin{tabular}{lllllllll}
\hline 95\% Lower & \multicolumn{4}{c}{ Exact } \\
\hline Variable & $\mathrm{X}$ & $\mathrm{N}$ & Sample $\mathrm{p}$ & Bound & P-Value \\
C.group.male & 3 & 17 & 0.176471 & 0.049898 & 0.999 \\
\hline
\end{tabular}

As indicated in table 5.6, 8 females out of 35 have changed. This number shows that about 22.85 percent of the learners have changed which cannot be considered as a significant change. This idea is also supported by Minitab because $\alpha$ is equal to 1.00 and $\mathrm{H} 0$ is accepted at both 0.05 and 0.1 level.

Table 5.6: Identity change in the female control group

\begin{tabular}{lcccccc}
\hline 95\% Lower & \multicolumn{5}{c}{ Exact } \\
\hline Variable & $\mathrm{X}$ & $\mathrm{N}$ & Sample $\mathrm{p}$ & Bound & P-Value \\
C.group.female & 8 & 35 & 0.228571 & 0.11914 & 1.000
\end{tabular}

The statistical procedures in the present study provided answers to different research questions. The first part which is related to the matter of identity change indicated that the first null hypothesis is accepted. The results of this part showed that the learners' identities in both control group and experimental group did not change significantly. This meant that exposure to foreign culture, beliefs, values, and roles could not change the identity type of learners effectively (though some of the learners' identities changed during this time and the amount of change were higher among learners in the experimental group in compare with learners in the control group). The findings of the present research to some extent are not in line with similar studies done in the field of identity by Erikson $(1958,1963)$, Abu-Rabia (1996), and Schumann (1978).

\section{Conclusions}

The findings of the present study answered the questions of identity change among learners of a foreign language after being exposed to the foreign language's cultural elements. The results of this study showed that the identity of the learners in both the control and the experimental groups did not change significantly except in cases where the experimental groups consisted of male participants. While it is generally believed that women are more susceptible to the second or foreign culture, the results of this study proved the contrary, meaning that male participants in the experimental group blended more into the target culture in comparison with their female counterparts. Mention should be made of the fact that the present findings cannot be surely generalized since the researchers had access to a limited number of participants. Flexibility of male learners towards foreign or second culture exposure can be an interesting topic for further analysis in future studies.

As an Islamic country with a relatively young population, Iran has become a center containing millions of young adults who are eagerly willing to learn different languages in order to communicate with the rest of the world. As an international lingua franca, English has been able to attract many young learners and serve as the cause of widespread growth of many language institutes. In the foreign language learning environment in Iran there has always been a growing concern about change caused in national and cultural identity due to foreign culture exposure in language learning environments. This concern is to the extent that educational policy makers have named this serious worry as cultural invasion and have thus tried to separate language from culture in schools and language institutes. They believe that teaching the culture to the learners will lead them to unconsciously assimilate into the target culture and consequently disregard their own as one that is inferior. The results of this study indicated that this skeptical view can be considered as rather groundless.

As the results of the present research indicate not only exposure to foreign culture, beliefs, values, and roles does not significantly change the identity types of the learners, but also it seems to give them an opportunity to become more 
conscious towards their native culture. In this regard current serious concerns about the weakening impacts of foreign culture exposure on national identity might be considered as too severe.

From a pedagogical point of view, the real challenge is how to create an atmosphere whereby cultural differences are objectively presented, managed, and utilized for more effective teaching of the language. The real threat, on the other hand, is how teachers support one culture or condemn the other on a certain subject which can be the target for further investigations in this field. Therefore, the results of this research indicate the fact that the pivotal dilemma lies in planning an appropriate syllabus for the EFL context by which means the learners are given the opportunity to become familiar with the cultural norms of the target language society along with that of their own and to adopt and/or adapt to the target culture in a manner that would not deteriorate their understanding and their perception of their own cultural identity but would rather strengthen it.

\section{References}

Abu-Rabia, S. (1996). Attitudes of Arab Minority Students in Israel and Canada Toward learning a Second Language. The Journal of Social Psychology, 136(4), 541-543.http://dx.doi.org/10.1080/00224545.1996.9714037

Alkire, Sabina. (2002). Dimensions of Human Development. World Development, 30(2), 181-205. http://dx.doi.org/10.1016/S0305-750X(01)00109-7

Anthis, Kristine \& C. LaVoie, Joseph. (2006). Readiness to change: A longitudinal studyof changes in adult identity. Journal of Research in Personality, 40, 209-219. http://dx.doi.org/10.1016/j.jrp.2004.12.004

Asref, M., R. (2002). Teaching English as a second or foreign language: The place of culture. Oxford University Press.

Bennion, L., \& Adams, G. (1986). A revision of the extended version of the objective measure of ego identity status: An identity instrument for use with late adolescents. Journal of Adolescent Research, 1(2), 183-197. http://dx.doi.org/10.1177/074355488612005

Berzonsky, M. D. (1990). Self-construction over the life-span: A process perspective on identity formation. In G. J. Neimeyer \& R. A. Neimeyer (Eds.). Advances in personal construct psychology, pp. 155-186. Greenwich, CT: JAI Press.

Erikson, E.H. (1959). Identity and the Life Cycle. New York: International Universities Press.

Erikson, E.H. (1963). Childhood and society, ( $2^{\text {nd }}$ ed.). New York: Norton.

Findley, C., V., \& Rothney, J., A. (1935). Twentieth Century World. The Ohio State University: Ohio, USA.

Grotevant, H. D. (1987). Toward a process model of identity formation. Journal of Adolescent Research, 2, 203e222.

Gu, M. (2010). National Identity in EFL Learning: A Longitudinal Inquiry. Changing English, 17(1), 57-67. http://dx.doi.org/10.1080/13586840903557076

Hassan, M., A. (2008). Teaching teachers: the importance of teaching the target culture to EFL teachers. TESL Reporter, 41(1), 45-55.

Hui, C. H., \& Triandis, H. C. (1986). Individualismecollectivism: A study of cross-cultural researchers. Journal of Cross-Cultural Psychology, 17, 225e248.

Kramsch, C. (1991). Culture in language learning: A view from the States. Foreign Language Research in Cross-cultural perspective. Amsterdam: John Benjamin.

Luke, A., \& Elkins, J. (1998). Reinventing literacy in "new times. Journal of Adolescent \& Adult Literacy, 42(1), 4-8.

Mantle-Bromley, C. (1997). Preparing students for meaningful culture learning. Foreign Language Annals, 25, 117-127. http://dx.doi.org/10.1111/j.1944-9720.1992.tb00519.x

Marcia, J. E. (1966). Development and validation of ego identity status. Journal of Personality and Social Psychology, 3(5), 551-558. http://dx.doi.org/10.1037/h0023281

Piller, I. (2007).Linguistics and intercultural communication. Language and Linguistics Compass, 1(3), 208-226. http://dx.doi.org/10.1111/j.1749-818X.2007.00012.x

Sabatier, C. (2008). Ethnic and national identity among second-generation immigrant adolescents in France: The role of social context and family. Journal of Adolescence, 31, 185-205. http://dx.doi.org/10.1016/j.adolescence.2007.08.001 
Schumman, John H. (1978). The acculturation model for second language acquisition. In: Gringas, Rosario C. (Ed.), Second language acquisition and foreign language teaching. Center for Applied Linguistics, Arlington, VA.

Seeyle, H. (1984). Teaching culture: strategies for inter-cultural communication. National Textbook Company: Lincolnwood, IL.Z

Singleton, David. (2000). Culture in Second Language Teaching and Learning. Book reviews, 28, 619-632.

Soenens, B., Duriez, B., \& Goossens, L. (2005). Social-psychological profiles of identity styles: Attitudinal and social cognitive correlates in late adolescence. Journal of Adolescence, 28, 107-125. http://dx.doi.org/10.1016/j.adolescence.2004.07.001

Stout, C.J. (2006). Arts-based Research and Ethical Self-consciousness.Second International Congress of Qualitative Inquiry. Champaign-Urbana. Retrieved Nov 5, 2009, from http://www.journal-writing.com

Appendix: EIPQ, English version

\begin{tabular}{|c|c|c|c|c|}
\hline Scales & Strongly & Agree & Slightly agree & Slightly disagree \\
\hline Points & 6 & 5 & 4 & 3 \\
\hline Disagree & Slightly disagree & & & \\
\hline 2 & 1 & & & \\
\hline
\end{tabular}

1. I have definitely decided on the occupation I want to pursue.

2. I don't expect to change my political principles and ideals.

3. I have considered adopting different kinds of religious beliefs.

4. There has never been to question my values.

5. I'm very confident about what kinds of friends are best for me.

6. My ideas about men's and women's roles have never changed as I become older.

7. I will always vote for the same political party.

8. I have firmly held views concerning my role in my family.

9. I have engaged in several discussions concerning behaviors involved in dating relationship.

10. I have considered different political views thoughtfully.

11. I have never questioned my view concerning what kinds of friends is best for me.

12. My values are likely to change in the future.

13. When I talk to the people about religion, I am sure to voice my opinion.

14. I'm not sure what type of dating relationship is best for me. 
15. I have not felt the need to reflect upon the importances I place on my family.

16. Regarding religion, my beliefs are likely to change in the near future.

17. I have defined views regarding the ways in which men and women should behave.

18. I have tried to learn about different occupational fields to find the best one for me.

19. I have undergone several experiences that made me change my views on men's and women's roles.

20. I have consistently re-examined many different values in order to find the ones which are best for me.

21. I think what I look for in a friend could change in the future.

22. I have questioned what kind of date is right for me.

23. I'm unlikely to alter my vocational goals.

24. I have evaluated many ways in which I fit into my family structure.

25. My ideas about men's and women's roles will never change.

26. I have never questioned my political views.

27. I have had many experiences that led me to review the qualities that I would like my friends to have.

28. I have discussed religious matters with a number of people who believe differently than I do.

29. I'm not sure that the values that I hold are right for me.

30. I have never questioned my occupational aspirations.

31. The extent to which I value my family is likely to change in the future.

32. My beliefs about dating are firmly held. 